\title{
L. The assumptions required for the proof of Avogadro's law
}

\section{Professor Tait}

To cite this article: Professor Tait (1887) L. The assumptions required for the proof of Avogadro's law, Philosophical Magazine Series 5, 23:144, 433-434, DOI: 10.1080/14786448708628032

To link to this article: http://dx.doi.org/10.1080/14786448708628032

册 Published online: 29 Apr 2009.

Submit your article to this journal

Џ Article views: 5

Q View related articles $\square$

Citing articles: 1 View citing articles 5 
Assumptions required for the Proof of Avogadro's Law. 433

$\mathrm{T}=$ The absolute temperature of the oil-bath.

$\mathrm{H}=$ Observed barometric height at the time of sealing.

$\mathrm{H}^{\prime}=$ The barometric pressure at the time of opening, corrected for pressure of vapour of water, at the

Then we have temperature of the water used in filling the tube.

$$
\begin{aligned}
& \frac{\mathrm{H}^{\prime}}{\mathrm{H}} \times \frac{w_{2}-w_{1}}{w_{2}}=\frac{273+t}{\mathrm{~T}}, \\
& \therefore \mathrm{T}=\frac{\mathrm{H} w_{2}(273+t)}{\mathrm{H}^{\prime}\left(w_{2}-w_{1}\right)} .
\end{aligned}
$$

In these experiments the observed values were, after making all corrections,

Hence

$$
\begin{aligned}
\mathrm{H} & =752 \cdot 4 \text { millim. } \\
\mathrm{H}^{\prime} & =744 \cdot 8 \% " \\
w_{2} & =5 \cdot 310 \text { grammes. } \\
w_{1} & =2 \cdot 278 \quad " \\
t & =15^{\circ} \mathrm{C} .
\end{aligned}
$$

$$
\mathrm{T}=\frac{752 \cdot 4 \times 5 \cdot 31 \times 288}{744 \cdot 8 \times 3 \cdot 032}=509 \text {. }
$$

And the temperature of the oil was therefore $509-273=$ $236^{\circ} \mathrm{C}$.

L. The Assumptions required for the Proof of Avogadro's Law. By Professor TAIT*

TWWO months ago (in consequence of a chance hint in 'Nature') I managed to procure a copy of Prof. Boltzmann's paper (antè, p. 305), and inserted a reply to it in the (forthcoming) Part II. of my investigations ; but, as there may be some delay in the publication, I send a short abstract to the Philosophical Magazine.

Prof. Boltzmann says that I do not expressly state that my work applies only to hard spheres. 'This is an absolutely unwarrantable charge, as I have taken most especial care throughout to make this very point clear.

Prof. Boltzmann, while objecting to my remark about "playing with symbols," has unwittingly furnished a very striking illustration of its aptness. His paper bristles throughout with formulæ, not one of which has the slightest direct bearing on the special question he has raised!

$\mathrm{He}$ asserts that, in seeking a proof of Clerk-Maxwell's Theorem, I have made more assumptions than are necessary. To establish this, he proceeds to show that the Theorem can

* Communicated by the Author.

Phil. Mag. S. 5. Vol. 23. No. 144. May 1887. $2 \mathrm{G}$ 


\section{Assumptions required for the Proof of Avogadro's Law.}

be proved by the help of a different and much more compre-

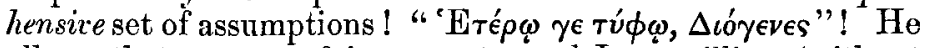
allows that my proof is correct; and I am willing (without reading it) to allow as much for his. The point at issue, then, is:-Which of us has made the fewer, or the less sweeping, assumptions? Another question may even be:-Whose assumptions are justifiable?

My assumptions are (formally) three, but the first two are expressly regarded as consequences of the third, which is thus my only one, viz. :-

There is free access for collision between each pair of particles, whether of the same or of different systems; and the number of particles of one kind is not overwhelmingly greater that that of the other.

From this I conclude (by general reasoning as to the behaviour of communities) that the particles will ultimately become thoroughly mixed, and that each system (in consequence of its internal collisions) will assume the "special state."

Prof. Boltzmann denies the necessity for internal collisions in either system, and assumes that (merely by colisions of particles of different kinds) uniform mixing, and distribution of velocities symmetrically about every point, will follow! Surely this requires proof, if proof of it can be given. So sweeping is the assumption that it makes no proviso as to the relative numbers of the particles in the two systems! The character of this absolutely tremendous assumption is so totally different from that of mine that it is impossible to compare the two. My assumption has, to say the least, some justification; but I fail to see even plausible grounds for admitting that of Prof. Boltzmann. There is no need to inquire as to its truth, at present; for I am not now discussing his extension of Maxwell's Theorem which, of course, is implied in it. The question is :-Is Prof. Boltzmann's assumption, even if correct, sufficiently elementary and obvious to be admitted as an axiom? It is so wide-reaching as, in effect, to beg the whole question ; and I venture to assert that, on grounds like these, it cannot possibly be shown that any of my assumptions are unnecessary.

The objection raised in Prof Boltzmann's "Second Appendix" (which is not in my German copy) was made long ago to me by Prof. Newcomb and by Messrs. Watson and Burbury. I have replied to this also in my Part II., and I will not discuss it now. I need only say that Prof. Boltzmann, while causelessly attributing to me a silly mathematical mistake, has evidently overlooked the special importance which I attach to the assumed steadiness of the "average behaviour of the various groups of a community." 